\title{
Vicente Ovalle, Camilo (2019). [Tiempo suspendido]: una historia de la desaparición forzada en México, 1940-1980. México: Bonilla Artigas. 394 pp.
}

\author{
Aleida García Aguirre \\ aleidagaguirre@gmail.com \\ Universidad Pedagógica Nacional del Estado de \\ Chihuahua. Departamento de Investigaciones \\ Educativas, Centro de Investigación y de Estudios \\ Avanzados del Instituto Politécnico Nacional, México
}

Cita sugerida: García Aguirre, A. (2021). [Revisión del libro [Tiempo suspendido]: una historia de la desaparición forzada en México, 1940-1980 por C. Vicente Ovalle]. Aletheia,

11(22), e095. https://doi.org/10.24215/18533701e095

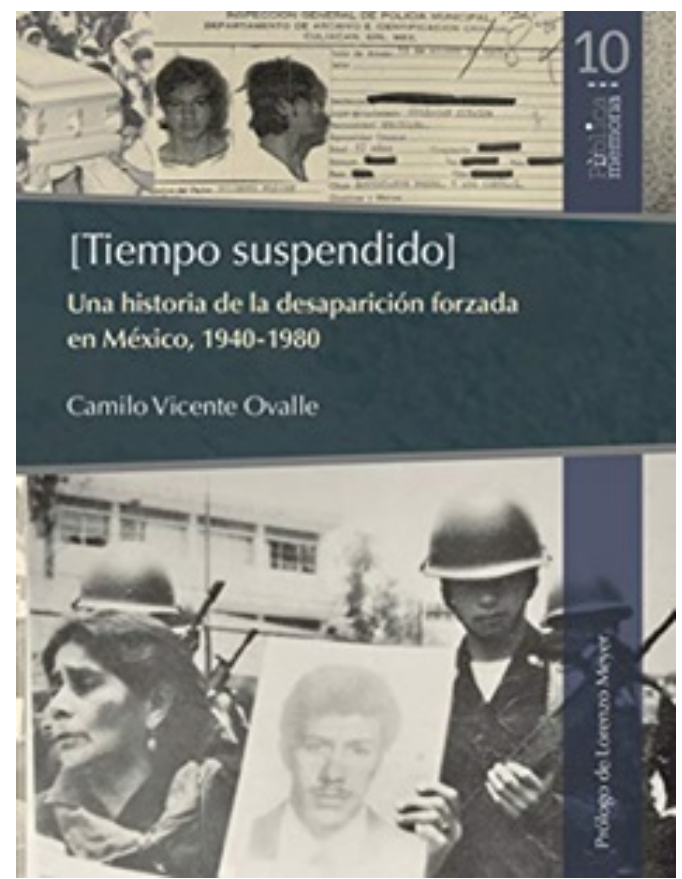


Camilo Vicente Ovalle es egresado de la Universidad Nacional Autónoma de México. Es originario de Juchitán, Oaxaca, un municipio destacado por su tradición de organización comunitaria y lucha social, herencia del autor. Para que lxs lectorxs fuera de México tengan elementos suficientes para atisbar la riqueza de esta obra, quiero señalar que Vicente Ovalle pertenece a una generación de historiadorxs que plantea críticas al canon historiográfico todavía dominante en México. En la práctica y de manera formal, esta generación declara que los linderos de la historia — como disciplina - llegan hasta el pasado reciente, y de manera decidida incursiona en el estudio de la violencia política de los años 60' hacia nuestro presente. Asimismo, esta generación retoma los señalamientos de disidentes políticos y familiares de víctimas de la violencia estatal, para combatir la tesis político-académica de la excepcionalidad del régimen mexicano en el contexto latinoamericano, pues ésta oculta las rutas del autoritarismo posrevolucionario y minimiza sus consecuencias sociales.

Lxs historiadorxs de esta generación se decantan en divergentes corrientes teórico-historiográficas y según las redes geopolíticas globales en las que se insertan. La violencia política del pasado reciente es un ámbito común a diferentes corrientes, pero las aproximaciones metodológicas y compromisos éticos las dividen. Una corriente pugna tácitamente por la continuación de la historia evenemencial: narra hechos políticos, políticomilitares y policiacos, fechas, y tilda a los sujetos como héroes o villanos, sustrayéndolos de sus mundos socio-culturales; estos intereses motivan sus acercamientos utilitarios a los testimonios, y la primacía de los acervos documentales. A contramano, la corriente que integra Vicente Ovalle, entreteje reflexiones teóricometodológicas críticas en las investigaciones sobre el pasado reciente. Para esta corriente, las historias que escribimos (los silencios y reiteraciones), resultan de las aproximaciones teórico-políticas con que leemos las fuentes y construimos problemas de investigación. Asimismo, advierte que los archivos de la represión son evidencia de las estructuras y desarrollos institucionales, antes que fuente de datos transparentes, y al mismo tiempo apuesta por la recuperación y el análisis ético de testimonios orales y escritos. El vínculo hacia los estudios del pasado reciente del Cono Sur, palpitan en esta segunda corriente y en la problematización que el autor ofrece sobre la desaparición forzada en México.

[Tiempo suspendido] es la primera obra de Vicente Ovalle. A un año de su publicación se ha consolidado como una lectura obligada para lxs investigadorxs de la violencia política del Estado contra las disidencias políticas en el pasado reciente. Se trata de una historia política y social de la desaparición forzada que, a su vez, abona para comprender los desarrollos de las políticas contrainsurgentes y su expansión a la población, cuestión que, en un presente marcado por ejecuciones extrajudiciales y desapariciones generalizadas, se revela decisiva. La obra está dividida en cuatro capítulos, pero los tres primeros pueden agruparse en una primera parte, y el último está constituido de tres apartados que podrían ser capítulos en sí mismos. En esta lógica, en los primeros tres capítulos, el autor organiza los argumentos generales y las discusiones conceptual-históricas sobre la desaparición forzada en México, la emergencia de una nueva disidencia política y la reorganización institucional y legal que dio paso a la contrainsurgencia y la despolitización de los disidentes políticos para su tratamiento judicial a lo largo de los años '70. En la segunda parte, el autor presenta tres estudios de caso (Oaxaca, Sinaloa y Guerrero) en los que moviliza el argumento de que los objetivos de la contrainsurgencia (y de la desaparición forzada dentro de esta) se dirigieron hacia la desarticulación o la eliminación de la disidencia, pero la evolución de una forma a otra no siguió una lógica cronológica ni generalizada por regiones, sino que respondió a los aprendizajes político-estratégicos de las instituciones y las definiciones ideológicas sobre los grupos insurgentes.

En el primer capítulo “Antes de 1968”, el autor argumenta que en los años 40’ las características autoritarias del régimen político mexicano estaban delineadas y a partir de entonces se consolidaron: partido hegemónico, control corporativo y desmovilización política. En este orden de cosas, la desaparición forzada, como una práctica más dentro de la violencia estatal, sirvió para la consolidación del Estado revolucionario, utilizada contra los opositores sin una brújula política clara. 
En el segundo capítulo, “La organización de los 'hombres perfectos'”, Vicente Ovalle delinea un argumento nodal: hacia 1965, emergió un nuevo tipo de disidencia política, resultado de una transformación subjetiva en sectores rurales y urbanos de una generación joven, que fundamentaba racional y afectivamente la lucha por un cambio social revolucionario. Paralelamente, las estructuras y marcos legales de las instituciones de seguridad nacional fueron reformadas para asegurar el orden político-económico. Entre estas transformaciones, destacan la creación de grupos especiales que no respondían a la estructura legal de las instituciones, el uso de instrumentos legales para definir a la disidencia política como "delincuencia organizada" y la coordinación entre instituciones hasta conformar un "complejo contrainsurgente" anticomunista, conceptualización que retoma de la historiografía existente. La conceptualización de Vicente Ovalle se distingue por señalar con claridad que la estrategia contrainsurgente implicó la participación del Poder Judicial, una rama del Estado que tradicionalmente ha quedado exenta de responsabilidades en la violencia política del pasado reciente.

En el tercer capítulo se concentra una de las aportaciones más relevantes de [Tiempo suspendido]: para Camilo Vicente la historia de la desaparición forzada precisa narrarse junto con la historia de la detención arbitraria, especialmente en los años setenta, cuando ambas se integraron en el "circuito de la detencióndesaparición", concepto que trascenderá la obra. El circuito estuvo conformado por tres procedimientos: aprehensión - detención - decisión final, y tuvo el objetivo de suspender al sujeto de su mundo social y de las regulaciones institucionales para que alimentara (con información y reconocimiento de campo) las estrategias contrainsurgentes. Suspender al sujeto, es decir, aprehenderlo y mantenerlo en detención clandestina por un periodo indeterminado de tiempo, no necesariamente resultaba en desaparición definitiva; esta decisión final dependió de las características intrínsecas de la práctica (particularmente del uso sistemático de la tortura), del momento político-estratégico de los grupos disidentes con los que el sujeto pudiera tener relación, de las dinámicas políticas regionales en curso durante la detención, y de las lecturas político-ideológicas que las instituciones involucradas hicieran del sujeto y su organización. Esto muestra que la evolución de la desaparición forzada en estrategia para la contrainsurgencia no fue lineal ni unívoca.

Ahora bien, la metodología de estudios de caso le permite a Vicente Ovalle fortalecer y complicar sus argumentos generales. Los casos de Oaxaca, Sinaloa y Guerrero son nodales para comprender que la transformación de la desaparición forzada de una táctica de violencia política (antes de '68) en una estrategia contrainsurgente, primero, y en una estrategia contra la población general en algunas zonas, después, no fue unívoca. Una especificidad de la violencia política del pasado reciente en México es que en un mismo tiempo coexistieron múltiples valoraciones ideológicas y acciones contrainsurgentes contra grupos de una misma organización político-militar, de acuerdo con la región, las acciones emprendidas, las trayectorias de los militantes, la experiencia de las instituciones. Los estudios de caso están hilados por un argumento general que se nutre de investigaciones previas, pero es articulado en un nuevo nivel: Las historias locales de organización política y comunitaria, movilización social, relaciones laborales, desarrollo industrial, propiedad de la tierra, relaciones entre niveles de gobierno, de escolarización y migración están entreveradas en el desarrollo y la integración estratégica de múltiples formas de violencia política, como el circuito de la detencióndesaparición, la constitución de cuerpos parapoliciales y paramilitares, el alcance social de la represión, la articulación entre instituciones judiciales y de seguridad nacional, y la participación de particulares en la represión política. Este argumento se asiste de otro más, igualmente central para el autor y la corriente de historiadorxs a la que pertenece: los procesos de radicalización política que dieron paso a la emergencia de un nuevo tipo de disidencia política, atendieron a estas mismas peculiaridades geopolíticas y cronológicas.

Para mostrar a lxs lectorxs la riqueza del trabajo desplegado en la segunda parte, me detendré en el estudio de caso del estado norteño de Sinaloa. El análisis avanza a contramano de las interpretaciones más difundidas sobre la radicalización de "los enfermos", un grupo de estudiantes universitarios y preparatorianos de la entidad que hacia 1973 se vinculó estrechamente con un núcleo de la Liga Comunista 23 de Septiembre (organización político-militar fundada en marzo del 73 que agrupó a diferentes agrupaciones a nivel 
nacional), característico por sus acciones contenciosas directas y su evolución hacia la lucha político-militar. Su radicalización, sostiene Vicente Ovalle, no estuvo desarticulada de los movimientos de "masas", por el contrario, se desarrolló dentro de experiencias de solidaridad con trabajadores agrarios y peticionarios de tierras en los años 1972-1974. Ahora bien, hasta 1974, en la represión contra las movilizaciones estudiantiles y de trabajadores agrarios de Sinaloa primaron la "contención" y la "desarticulación"; mientras que la articulación estratégica de la desaparición forzada para la eliminación de la disidencia se consumó como "solución definitiva" a partir de 1976, cuando después de dos años desarticulados, los enfermos reemergieron y el objetivo de eliminación que ya se había desarrollado contra grupos-regiones de Oaxaca y Guerrero, fue adaptado considerando la experiencia contrainsurgente sinaloense. A partir de 1976, pero decididamente desde 1978, la coexistencia de una estrategia contrainsurgente de eliminación de la disidencia con el combate contra el narcotráfico resultó en el desvanecimiento de la frontera política en el uso de la desaparición forzada como estrategia estatal, y ésta fue implementada contra la población general. Esta "despolitización" de la desaparición forzada, no obstante, conserva en su núcleo la práctica política de (des)calificar cuáles vidas son vivibles.

El trabajo de Vicente Ovalle tiene la huella de los estudios del pasado reciente, y esta se destaca en el estudio de Sinaloa: un pasado que no termina por ser "pasado", pues en él identificamos estructuras, instituciones, prácticas y sujetos que interpelan nuestro presente directamente. Las investigaciones subsecuentes deberán atender los hallazgos de Vicente Ovalle sobre el desarrollo histórico de instituciones responsables de violaciones graves a derechos humanos (léase Dirección Federal de Seguridad, agencia de espionaje y epicentro del grupo especializado en estrategias de terrorismo de Estado) hoy desmanteladas; pero al mismo tiempo, los estudios sobre las violencias generalizadas del presente (con marcas de clase, raciales y de género) precisarán estrechar relaciones con el campo de estudio que Vicente Ovalle consolida en [Tiempo suspendido]. Leída desde el Cono Sur, esta obra continuará develándose como un referente primordial para las nuevas interpretaciones del pasado reciente latinoamericano. 